\title{
Reactive Power Control of DFIG Wind Turbines for Power Oscillation Damping under a Wide Range of Operating Conditions
}

\author{
Mohamed Edrah, K.L. Lo, Olimpo Anaya-Lara \\ Department of Electrical and Electronic Engineering, University of Strathclyde, \\ 204 George Street, Glasgow G1 1XW, UK \\ E-mail: mohamed.edrah@strath.ac.uk
}

\begin{abstract}
This paper analyses the effect of replacing existing synchronous generators equipped with power system stabilizers (PSS) by DFIG based wind farms on the damping of power system oscillations in a multi-machine power system. A power system stabiliser was designed to enhance the capability of DFIG to damp power systems oscillations. The validity and effectiveness of the proposed controller are demonstrated on the widely used New England 10machine 39-bus test system that combines conventional synchronous generators and DFIG based wind farms using eigenvalue analysis and nonlinear simulation. The nonlinear simulation is used to demonstrate how the damping contribution of DFIG based wind farms is affected by different operating conditions within the same wind farm and stochastic wind speed behaviour. The results show that installing conventional fixed parameters PSS within reactive power control loop of DFIG rotor side converter has a positive damping contribution for a wide range of operating conditions. Furthermore, the results clearly show that DFIG based wind farms equipped with the proposed farm level PSS can damp power system oscillations more effectively than synchronous generators PSS.
\end{abstract}

Keywords: Power system oscillations, power system stabilizer (PSS), doubly fed induction generator (DFIG), small signal stability, transient stability.

\section{Introduction}

Wind power penetration levels have significantly increased during the last decades. According to the Global Wind Energy Council, the installed wind power capacity worldwide has exceeded 
$318 \mathrm{GW}$ at the end of 2013 and will reach about $712 \mathrm{GW}$ by 2020 [1]. As wind power penetration into power systems increases additional integration considerations are needed and the most important ones are fault ride through capability, power oscillations damping and voltage support capabilities during network disturbances. All have are of direct concern to system stability. Poor damping of power oscillations and lack of reactive power support can deteriorate system stability and lead to blackouts [2].

Currently, the most widely used wind turbine technology worldwide is doubly fed induction generator (DFIG) [3]. This type of wind turbines is not synchronously connected to the grid, hence they do not directly engage in power systems electromechanical oscillations nor do they produce new oscillatory modes [4], [5]. However, with the rapid increment of wind power penetration, DFIG wind turbines can affect the overall damping performance when replacing synchronous machines which are equipped with power system stabilizers (PSSs) [6]. Therefore, damping contribution of installed wind turbines is of significant important and this can be achieved by introducing an auxiliary PSS loop into the DFIG controller [5].

In recent years, several researchers have examined the capability of DFIGs for damping power oscillations [4-10]. In [6-10] an auxiliary DFIG damping controller within the active power controller is proposed. The results show that DFIG wind turbines equipped with PSS are able to damp low-frequency power system oscillations effectively. However, the controllers used in [7] and [9] are based on rotor flux magnitude and angle control (FMAC) approach which is different from the standard widely used vector control approach in commercial DFIG wind turbines [11]. Moreover, the damping of DFIG wind turbines shaft mode can be decreased, mechanical loads increases and mechanical system lifespan is reduced when active power modulation is used to damp power system oscillations [12]. Furthermore, reference [13] reported that the use of active power to damp system oscillations is adversely influenced by torque variations due to tower shadow. In addition, as wind turbines are required to support grid voltage, the effectiveness of using active power PSS can be degraded [10].

As DFIGs are able to control real power and reactive power independently, reactive power modulation can be used to regulate the voltage and enhance their capability to damp power oscillations. Only a few papers have been published regarding attached PSSs to the reactive power controller of DFIGs to damp post-fault oscillations [12],[14-16]. The results presented in these papers show that DFIGs can effectively damp power system oscillations using an 
additional control attached to the reactive power control circuit. However, none of them takes into account the impact of the stochastic wind speed behaviour on the proposed damping controller. Moreover, the studies carried out in [12] and [14, 15] do not consider the effect of the crowbar circuit when controlling both reactive and real power is deactivated and a large amount of reactive power is absorbed.

In this paper, a comprehensive analysis is conducted to show the effect of replacing existing synchronous generators (SGs) equipped with PSSs by DFIG based wind farms on the damping of power system oscillations in a multi-machine power system. A power system stabiliser was designed to evaluate the capability of DFIGs to damp power systems oscillations. To avoid the negative effects of PSS active power modulation, a reactive power modulation PSS using a comprehensive system model is modelled and proposed in this study. As wind power is stochastic and fluctuates with the variation of wind speed, the capability of a wind farm to damp power system oscillations may be reduced. Therefore, the proposed conventional fixed parameters PSS should have the capability to damp power oscillations effectively under nonuniform variable wind speeds across the wind farm. The feasibility of the proposed fixed parameters PSS is evaluated using the New England 10-machine 39-bus test system taking into account the non-uniform and variable wind speed profiles.

The paper is organized as follows. Section 2 presents the modelling of DFIG used in this study. DFIG proposed damping controller is described in Section 3. Section 4 presents the test system. The results and discussion are presented in Section 5. Finally, Section 6 summarises the main outcomes of this work.

\section{Modelling of DFIG}

The typical overall DFIG wind turbine structure is shown in Fig. 1 in which DFIG wind turbine comprises a wound rotor induction generator and back-to-back converters. The stator windings of the induction generator are connected directly to the grid while the rotor windings are connected to the grid via the back-to-back converter, which consists of the rotor and the grid sided converters (RSC) and (GSC). The power rating of the back-to-back converter is about $20 \%$ to $30 \%$ of the DFIG rating. With these converters, DFIG wind turbines can generate active power over a wide range of rotational speeds around the synchronous speed at constant voltage and frequency. Therefore, the magnitude and direction of the active power that flows between 
the rotor and the grid is controlled. The induction generator is linked to the wind turbine through a mechanical shaft system consisting of a high and a low speed shaft connected by a gearbox. A crowbar system is used in the event of over current to protect the converters and to achieve continuous operation of the DFIG.

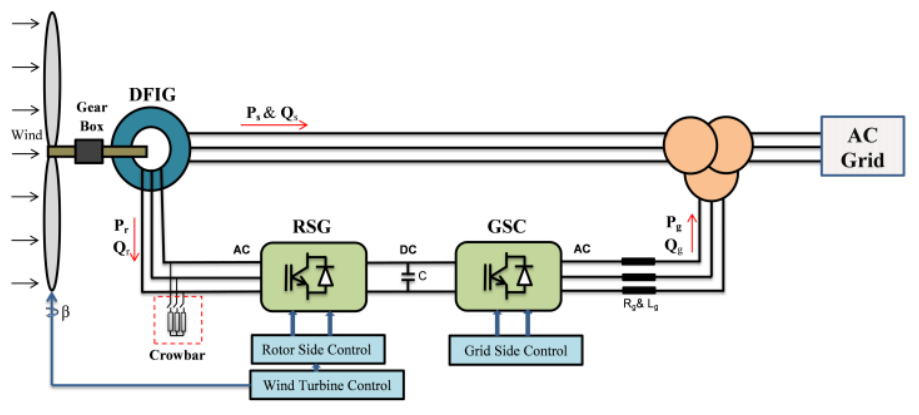

Fig. 1 overall DFIG wind turbine structure.

The instantaneous active and reactive power $\left(P_{s}, Q_{s}\right)$ of the DFIG stator can be controlled independently by the RSC as shown in Fig. 2(a). Regulating the DFIG terminal voltage can be achieved by using the stator side reactive power. The main purpose of the GSC is to maintain the converter dc link voltage within its acceptable limits and can be used to control the reactive power flow between the GSC and the grid as shown in Fig. 2(b). Both converters can be modelled as current controlled voltage source converters. There are several ways to control and supply a sinusoidal current at rotor frequency. The common approach is to use pulse width modulation (PWM) [17]. 


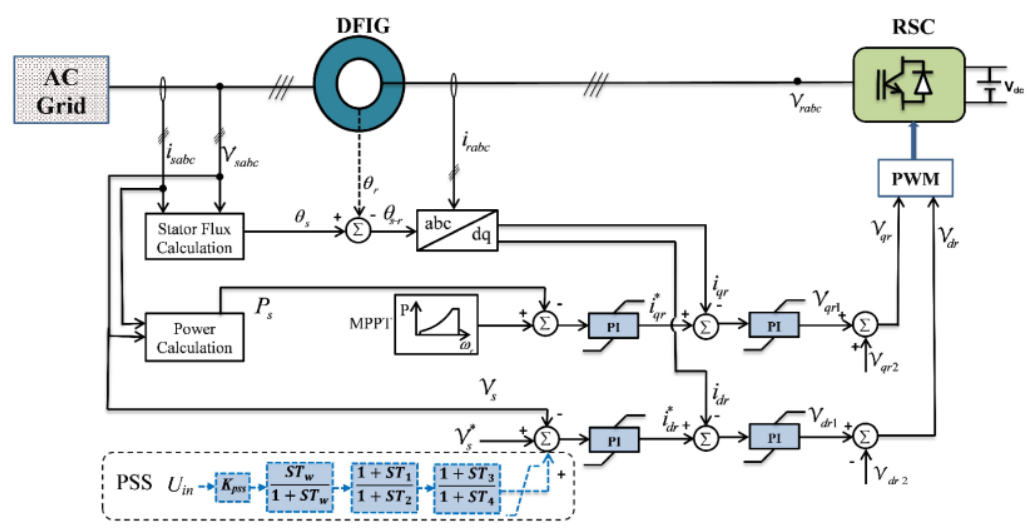

(a)

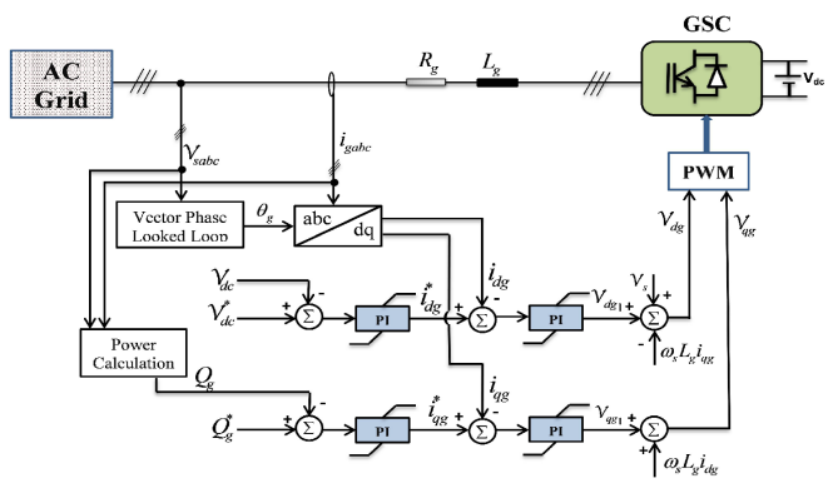

(b)

Fig. 2 DFIG vector control scheme, a) RSC with the proposed PSS (dashed blue lines), b) GSC

The outer control loop of the RSC regulates independently both the DFIG stator real power $P_{s}$ and reactive power $Q_{s}$. The error signals generated from comparing reference signals with measured signals of reactive and active power are passed through proportional integral (PI) controllers to generate reference signals $i_{q r}^{*}$ and $i_{d r}^{*}$ of the $d q$ axes current components respectively. These signals are compared to the measured current signals $i_{d r}$ and $i_{q r}$ in the $d q$ axes to form two voltage signals by the inner control loops. These voltage signals are compensated by the corresponding cross coupling voltage in $d q$ axes to create $v_{d r}$ and $v_{q r}$ respectively. The generated voltage signals $v_{d r}$ and $v_{q r}$ are then passed to a pulse width modulation (PWM) [18], [19].

In a similar way, DFIG-GSC outer control loop regulates the converter dc link voltage and the reactive power exchanges between the grid and the GSC to generate reference current signals $i^{*} d g$ 
and $i_{q g}^{*}$ of $d q$ axes current components respectively. These signals are compared to measured current signals $i_{d g}$ and $i_{q g}$ in the $d q$ axes to form two voltage signals by the inner control loops. These voltage signals are compensated by the corresponding voltage in $d q$ axes to generate $d q$ voltage signals $v_{d g}$ and $v_{q g}$ respectively [18], [19].

\section{DFIG proposed damping controller}

This section presents the design of a controller for DFIG based wind turbines to improve the damping of power system oscillations. The main function of the damping controller is to damp low-frequency power oscillations between 0.1 and $2 \mathrm{~Hz}$, which are identified as local or interarea modes. The widely used conventional PSS is employed in the DFIG-RSC as shown in Fig. 2(a) with dotted blue lines. The output signal of PSS is attached to the reactive power controller within RSC to help increasing the damping torque by controlling the reactive power produced by DFIG. The amplitude of oscillations can be reduced by changing the DFIG terminal voltage during the forward or the backward swing.

The conventional PSS consists of a stabilizer gain $K_{p s s}$, a washout filter with time constant $T_{w}$ (s), a second-order lead lead-lag compensator with time constants $T_{1}$ to $T_{4}$ (s), and an output limiter. The gain determines the amount of damping introduced by the damping controller. The single washout filter with time constant $T_{w}=10 \mathrm{~s}$ is a high pass filter used to allow a certain range of frequency and is anticipated to be active only through transient periods. The two-stage compensator block provides an appropriate lead or lag phase of the output signal in order to enhance the damping of power system oscillations. The limiter is used to assure that the output signal is under the control limits. In this study, the values of the limiter is set to $\pm 0.1 \mathrm{pu}$. The transfer function of the PSS can be expressed by equation (1) [20].

$$
u_{p s s}=K_{p s s}\left(\frac{S T_{w}}{1+S T_{w}}\right)\left(\frac{1+S T_{1}}{1+S T_{2}}\right)\left(\frac{1+S T_{3}}{1+S T_{4}}\right) u_{i n}
$$

where, $u_{i n}$ and $u_{p s s}$ are input and output signals of the controller respectively, $K_{p s s}$ is the gain, $T_{w}$ is a washout time constant (seconds) and $T_{1}$ to $T_{4}$ are time constants of lead-lag compensator (seconds). 
In order to enhance the damping of the poorly damped low frequency oscillations, critical oscillatory modes have to be modified. Therefore, the poorly damped oscillatory modes must be excited by the chosen input signal and have to be visible in the chosen output signal. Input signals with higher magnitude of residue are more effective for damping the oscillatory modes [21].

Residue approach, which has been used for designing PSSs in synchronous generators, can also be used for designing PSSs for DFIG based wind turbines. The feedback signal and phase angle that needs to be compensated can be determined by the residue approach. Residue is a comprehensive index that measures the degree in which the selected mode is influenced by the controller. The residue $R_{i}$ corresponding to a particular eigenvalue $i_{t h}$ for a transfer function between a selected input $u$ and output $y$ can provide a measure of the mode's sensitivity to the feedback control. Therefore, the residue method can give an indication of how the modes will be affected by the feedback control. Moreover, the residue is a complex value and thus the angle gives the direction in which the root locus leaves the associated pole. Hence the required phase compensation between the input and output of PSS can be calculated by the residue angle to give a positive contribution to the damping of the selected mode [22]. Fig. 3 shows a schematic illustration of the required phase compensation, where $\angle R i$ represents the phase angle of residue $R_{i}$ and $\angle H i$ represents the PSS transfer function phase angle respectively.

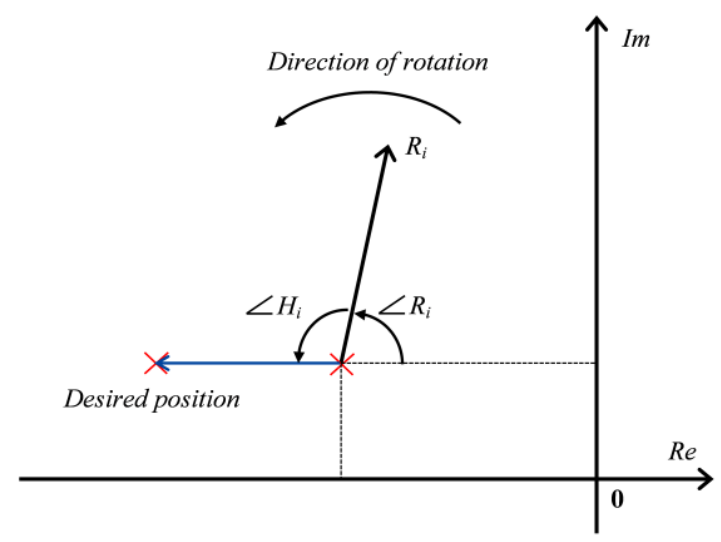

Fig. 3 Schematic illustration of compensation concept. 
As DFIG wind turbines are to some degree decoupled from the rest of the grid, the produced active power and the machine speed signals of DFIG wind turbines are not sensitive to the system oscillations. Moreover, these two signals are affected by tower shadow and torque variations. To avoid the use of wide area communications, the available local signals such as the deviations in pu of the DFIG based wind farm terminal voltage and frequency are examined using residue analysis. The mode's sensitivity to input signal of PSS can be provided by the residue of any specific mode. In [2], detailed information of how to calculate the residues from a transfer function is given. The required phase angle compensation and the time constants can be taken from [23]:

$$
\left\{\begin{array}{l}
\varphi_{\text {comp }}=180^{\circ}-\angle R i \\
\alpha_{c}=\frac{T_{\text {lead }}}{T_{\text {lag }}}=\frac{1-\sin \left(\frac{\varphi_{\text {comp }}}{m_{c}}\right)}{1+\sin \left(\frac{\varphi_{\text {comp }}}{m_{c}}\right)} \\
T_{\text {lag }}=\frac{1}{\omega_{i} \sqrt{\alpha_{c}}}, \quad T_{\text {lead }}=\alpha_{c} T_{\text {lag }}
\end{array}\right.
$$

Where $\varphi_{\text {comp }}$ is the required phase angle compensation, $\angle R i$ represents the phase angle of residue $R_{i}$ and $m_{c}$ represents the number of lead-lag blocks.

Based on residue analysis results, frequency deviation signal is carefully chosen for successful damping of oscillations. The output signal of the PSS is connected to the DFIG-RSC reference voltage signal as can be seen in Fig. 2(a).

The results of detailed small signal stability analysis conducted on the test system show that in case 3 (SGs G7, G9 in case 2 are replaced by equivalent DFIG-based wind farms) there is a critical mode $(-0.149 \pm \mathrm{j} 6.85)$ oscillating at $1.093 \mathrm{~Hz}$ with a damping factor of $2.2 \%$. To move this critical mode away from the right-hand side of the complex plane the DFIG that replaced G7 has to be fitted with a power system stabiliser.

To calculate the residue's phase angle $\angle R i$ of the critical mode, the PSS is only implemented with a constant gain $K_{p s s}$ and washout filter with time constant $\mathrm{T}_{\mathrm{w}}=10$ s. No phase compensation 
blocks are involved at the moment. For different gain values, the critical mode must move in a straight-line direction as defined by the residue. The analysis was performed under different gain values. The result shows that the residue's phase angle is $10.71^{\circ}$. In this case, the phase compensation blocks have to introduce a phase shift of $10.71^{\circ}$ at $1.093 \mathrm{~Hz}=6.867 \mathrm{rad} / \mathrm{s}$ (the frequency of the critical mode).

Employing equation (2) the $\mathrm{T}_{\text {lead }}$ and $T_{\text {lag }}$ will be $0.1599 \mathrm{~s}$ and $0.1325 \mathrm{~s}$ respectively.

To define the value $K_{p s s}$, the gain increased incrementally from 0 to 200 and recorded against the mode. The best gain of 120 was obtained against the critical mode.

The parameters of DFIG2 can be obtained by repeating the same process. The PSS parameters for both SGs and DFIG are given in Table 3 in the Appendix.

\section{Test system}

The widely used New England 10-machine 39-bus system has been chosen as the test system in this study as shown in Fig. 4 [24]. The system consists of 10 SGs in which G1 is an equivalent external generator, 12 transformer, 46 transmission lines and 19 loads modelled as nonlinear ZIP loads (constant impedance $Z$, current $I$ and power $P$ ) [25]. Every synchronous machine is equipped with (TGOV1) turbine governor and (IEEEX1) exciter. However, only synchronous generators G5, G7, G9 are fitted with (STAB1) PSS. The PSSs parameters, which are obtained by using the method mentioned in Section 3, are given in Table 3 (Appendix). The static and dynamic data of New England 10-machine 39-bus system can be found in [24]. 


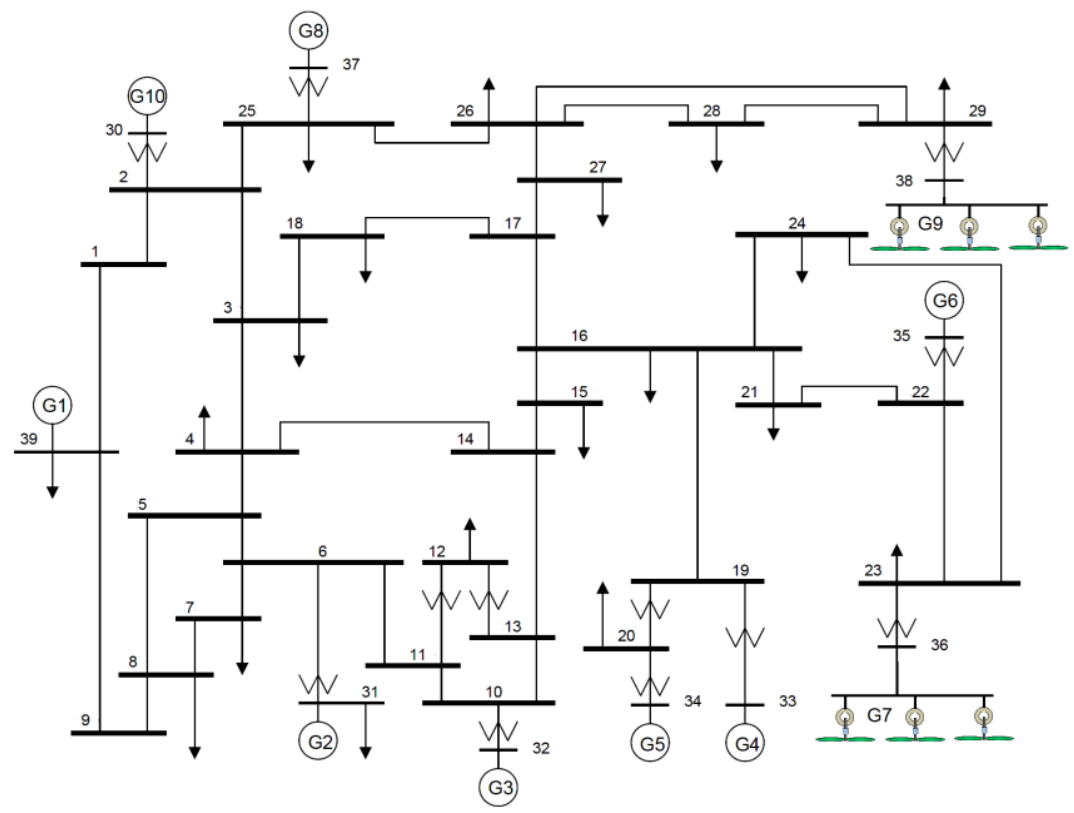

Fig. 4 Single line diagram of the New England 10-machine 39-bus system and the location of two DFIG based wind farms.

To examine the contribution of installed wind turbines toward power oscillations damping, two large-scale DFIG wind farms equipped with PSS are installed in the test system to replace two large synchronous machines G7 and G9. The total generated power from the two wind farms accounts for $22.6 \%$ of the total consumed power of the used test system.

Each of the wind farms contains a large number of DFIG wind turbines. By modelling every turbine in the farm in the simulation tool, the complexity of the system and simulation time increases. Therefore, an aggregation technique is applied to decrease the large number of presented turbines. In many published papers the simplest aggregation technique is used and it represents the whole wind farm as a single large wind turbine [26].

This simple aggregation method assumes that all wind turbines within the wind farm are receiving the same wind speed and thus operating at the same operating point to produce the same power. However, in practice, the powers produced by wind turbines are different depending on wind speed variation and their location inside the wind farm due to the wake effect. Hence a multi-machine equivalent method is used in this paper and it is more accurate when the turbines within the wind farm are facing different wind speeds [27]. 
In the second study scenario of cases $3 \& 4$, every wind farm is represented by three DFIG based wind turbines each operating at different operating points which are defined in Table 1. Moreover, each wind farm is exposed to a short-term wind speed variation which is a measured wind speed obtained by [3] from wind turbine manufacturers. Fig. 5(b\&c) shows the wind speed patterns for both scenarios. The two wind farms and the test system are modelled in detail and simulated by using NEPLAN software [28].

Table 1 Different modes of operation of two wind farms

\begin{tabular}{|c|c|c|c|c|c|c|}
\hline $\begin{array}{l}\text { Wind } \\
\text { Farm }\end{array}$ & Group & $\begin{array}{c}\text { Operation } \\
\text { Mode }\end{array}$ & $\begin{array}{c}\text { Wind } \\
\text { Pattern }\end{array}$ & $\begin{array}{l}\text { Stator } \\
\text { Power }\end{array}$ & $\begin{array}{l}\text { Rotor } \\
\text { Power }\end{array}$ & $\begin{array}{l}\text { Total } \\
\text { Power }\end{array}$ \\
\hline \multirow{3}{*}{ I } & A & $\begin{array}{c}\text { Super- } \\
\text { synchronous }\end{array}$ & $\begin{array}{c}\text { Fig.5(b) } \\
\text { DFIG1 }\end{array}$ & 240 & 36 & 276 \\
\hline & B & Normal & $\begin{array}{l}\text { Fig.5(b) } \\
\text { DFIG2 }\end{array}$ & 167 & -2 & 165 \\
\hline & $\mathrm{C}$ & $\begin{array}{c}\text { Sub- } \\
\text { synchronous }\end{array}$ & $\begin{array}{l}\text { Fig.5(b) } \\
\text { DFIG3 }\end{array}$ & 139 & -21 & 118 \\
\hline \multirow{3}{*}{ II } & A & $\begin{array}{c}\text { Super- } \\
\text { synchronous }\end{array}$ & $\begin{array}{l}\text { Fig.5(c) } \\
\text { DFIG4 }\end{array}$ & 350 & 53 & 403 \\
\hline & B & Normal & $\begin{array}{l}\text { Fig.5(c) } \\
\text { DFIG5 }\end{array}$ & 245 & 3 & 248 \\
\hline & $\mathrm{C}$ & $\begin{array}{c}\text { Sub- } \\
\text { synchronous }\end{array}$ & $\begin{array}{l}\text { Fig.5(c) } \\
\text { DFIG6 }\end{array}$ & 206 & -31 & 175 \\
\hline
\end{tabular}



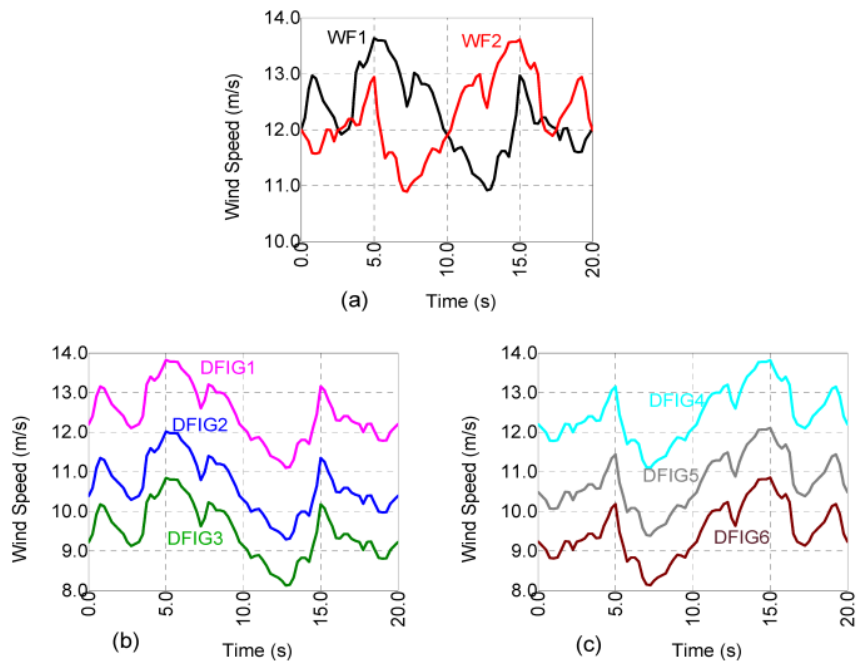

Fig. 5 Wind speed patterns for (a) wind farms I\& II in scenario A, (b) wind farm I in scenario B, (c) wind farm II in scenario $B$.

\section{Results and discussion}

In this study, four different cases and two scenarios are examined by small signal and transient stability to show the effects of replacing existing SGs equipped with PSSs by DFIG based wind farms have on the power oscillations damping, and to show the effectiveness of the proposed DFIG PSSs.

The explanation of each case is:

- Case 1: All generators are conventional SGs without PSSs. It is the base case.

- Case 2: SGs G5, G7, G9 are each equipped with a PSS. The location of the PSSs used for synchronous generators is selected based on participation factor for each generator except G1, which is the equivalent external generator.

- Case 3: SGs G7, G9 in case 2 are each replaced by an equivalent DFIG based wind farm without the proposed PSS whereas synchronous generator G5 is still equipped with its PSS.

- Case 4: SG G7, G9 in case 2 are each replaced by an equivalent DFIG based wind farm equipped with the proposed PSS.

For the two wind farms in cases $3 \& 4$, two scenarios are included and are described below: 
- Scenario A: each wind farm is represented as a single aggregated DFIG model operating at super-synchronous mode. The proposed conventional fixed parameters PSS for each DFIG based wind farm is designed based on this scenario. Moreover, to show the effect of wind speed variation on DFIG PSS, each wind farm is exposed to a different wind speed variation as shown in Fig. 5(a).

- Scenario B: Each wind farm is represented as three aggregated DFIG model operating at different modes as shown in Table 1. In this scenario, the three aggregated groups in each wind farm are equipped with the proposed conventional fixed parameters PSS that used in Scenario A. Moreover, each wind farm is exposed to a different wind speed variation as shown in Fig. 5(b) and (c).

\section{A. Small signal stability analysis}

A comprehensive small signal stability analysis was conducted on the used system for the four cases and the two scenarios. The main eigenvalues with damping factors less than $10 \%$ for each case and the two scenarios are presented in Table 2. It is clear that the test system without any PSS is unstable as there are two oscillatory modes that possess positive real parts. Negative damping factors indicate that there are two growing oscillatory modes which can lead to system instability. The mode shape analysis of first mode shows that there are two groups of generators dominated by G9 and G5 swinging against each other. However, in the second case, in which SGs G5, G7 and G9 are equipped with PSS, the system is stable as the unstable modes are damped by the selected PSSs.

Table 2 Main electromechanical modes

\begin{tabular}{|c|c|c|c|c|c|}
\hline Case & Scenario & $\begin{array}{c}\text { Eigenvalue } \\
\lambda=\sigma+\mathrm{j} \omega(\mathrm{pu})\end{array}$ & $\begin{array}{c}\text { Damping } \\
\text { Factor } \zeta(\%)\end{array}$ & $\begin{array}{c}\text { Frequency } \\
\mathrm{f}(\mathrm{Hz})\end{array}$ & Dominant Machine \\
\hline \multirow{5}{*}{1} & \multirow{5}{*}{-} & $0.135 \pm \mathrm{j} 5.63$ & -2.4 & 0.896 & G09, G05 \\
\hline & & $0.047 \pm \mathrm{j} 3.70$ & -1.3 & 0.589 & $\begin{array}{c}\text { G01, G05, G06, G09, } \\
\text { G04 }\end{array}$ \\
\hline & & $-0.024 \pm \mathrm{j} 5.71$ & 0.4 & 0.909 & $\begin{array}{c}\text { G05, G02, G09, G08, } \\
\text { G01 }\end{array}$ \\
\hline & & $-0.146 \pm j 6.82$ & 2.1 & 1.086 & G03,G02 \\
\hline & & $-0.171 \pm \mathrm{j} 6.29$ & 2.7 & 1.002 & G06. G07, G02, G05 \\
\hline
\end{tabular}




\begin{tabular}{|c|c|c|c|c|c|}
\hline & & $-0.37 \pm j 7.84$ & 4.7 & 1.247 & G04 \\
\hline & & $-0.414 \pm \mathrm{j} 8.07$ & 5.1 & 1.284 & G07, G06 \\
\hline & & $-0.64 \pm j 7.97$ & 8.0 & 1.269 & G08, G10 \\
\hline \multirow{4}{*}{2} & \multirow{4}{*}{ - } & $-0.151 \pm j 6.83$ & 2.2 & 1.086 & G03, G02 \\
\hline & & $-0.264 \pm j 6.16$ & 4.3 & 0.98 & G02, G03, G06 \\
\hline & & $-0.654 \pm \mathrm{j} 7.53$ & 8.7 & 1.199 & G04,G06, G05 \\
\hline & & $-0.683 \pm j 7.99$ & 8.5 & 1.272 & G08, G10 \\
\hline \multirow{16}{*}{3} & \multirow{8}{*}{ A } & $-0.149 \pm j 6.85$ & 2.2 & 1.091 & $\bar{~} \mathrm{G} 03, \mathrm{G} 02$ \\
\hline & & $-0.19 \pm j 3.89$ & 4.9 & 0.619 & G01, G05, G06, G04, \\
\hline & & & & & G03 \\
\hline & & $-0.354 \pm \mathrm{j} 6.22$ & & & G02, G06, G03, G05, \\
\hline & & & 5.7 & 0.99 & G10 \\
\hline & & $-0.52 \pm j 7.821$ & 6.6 & 1.245 & G04, G06 \\
\hline & & $-0.625 \pm \mathrm{j} 6.87$ & 9.1 & 1.094 & G06, G10, G08 \\
\hline & & $-0.717 \pm j 7.93$ & 9 & 1.262 & G08, G10 \\
\hline & \multirow{8}{*}{ B } & $-0.145 \pm \mathrm{j} 687$ & 2.1 & 1.093 & G03, G02 \\
\hline & & $-0.198 \pm \mathrm{j} 3.89$ & 5.1 & 0.619 & G01, G05, G06, G04, \\
\hline & & & & & G03 \\
\hline & & $-0.345 \pm j 6.22$ & 5.5 & 0.99 & G02, G06, G03, G05, \\
\hline & & & & & G10 \\
\hline & & $-0.521 \pm j 7.82$ & 6.6 & 1.245 & G04 \\
\hline & & $-0.628 \pm j 6.87$ & 9.1 & 1.094 & G06, G10, G08 \\
\hline & & $-0.716 \pm j 7.93$ & 9 & 1.262 & G08, G10 \\
\hline \multirow{6}{*}{4} & \multirow{3}{*}{ A } & $-0.445 \pm j 6.63$ & 6.7 & 1.056 & G03, G02, G06, G10 \\
\hline & & $-0.519 \pm \mathrm{j} 7.82$ & 6.6 & 1.244 & G04 \\
\hline & & $-0.722 \pm j 7.98$ & 9.0 & 1.271 & G08, G10 \\
\hline & \multirow{3}{*}{ B } & $-0.527 \pm j 7.81$ & 6.7 & 1.244 & "G04 \\
\hline & & $-0.538 \pm j 6.60$ & 8.1 & 1.051 & G03, G02, G06, G10 \\
\hline & & $-0.611 \pm j 7.98$ & 7.6 & 1.27 & G08, G10 \\
\hline
\end{tabular}


Small signal stability results indicate that replacing synchronous generators equipped with PSSs (case 2) by an equivalent DFIG based wind farms (case 3) can have a negative impact on the damping of power system oscillations as shown in Table 2. Although the two installed wind farms do not participate in electromechanical oscillations, the number of modes with a damping factor of less than $10 \%$ increased from 4 in case 2 to 6 in case 3 . The small signal stability results show that the two scenarios in case 3 are very similar. It is interesting to note that in this case representing the whole wind farm as a single aggregated DFIG has a similar impact on power system small signal stability as that of representing the wind farm as three aggregated DFIGs operating at different modes.

Although the installed wind farms are not synchronously coupled to the test system they can provide a damping effect if they are equipped with PSSs as shown in case 4. In this case, the stability of the test system is improved in comparison to previous cases and in which no damping factor less than $6.7 \%$ is observed. There are three modes in Scenario A which have a similar frequency and are dominated by the same machine to that in Scenario B. However, the damping factors of the two modes are slightly different.

\section{B. Transient stability simulation}

To evaluate the effectiveness of the damping controller under variable wind speeds, the four cases and two scenarios are simulated by a nonlinear simulation and therefore and a grid fault has to be simulated. The location of the grid fault is chosen to be near critical bus 16 . A permanent fault of $150 \mathrm{~ms}$ three phase to ground is applied at $\mathrm{t}=0.1 \mathrm{~s}$ near critical bus 16 on transmission line 16-24. The fault was isolated by isolating the faulted line from both sides simultaneously.

The rotor angles of each synchronous machine relative to the largest SG (G1) rotor angle, which is used as a reference rotor angle, are monitored. Fig. 6 (a) shows the rotor angles of G2 to G10 with respect to that of G1 in the first case where all PSSs are disconnected. It is clear that the amplitude of the oscillation is growing up with time leading to system instability. As mentioned in the small signal stability analysis that G9 is dominating the first unstable oscillatory mode, G9 loses its synchronism after $11 \mathrm{~s}$ in the nonlinear transient stability simulation. However, the system stability can be reached by installing PSSs in G5, G7 and G9 as shown in Fig. 6(b). This figure shows that the variations of SGs rotor angles in case 2 are better 
that in case 1 . The unstable modes in the previous case are damped by the installed PSSs leading to system stability.

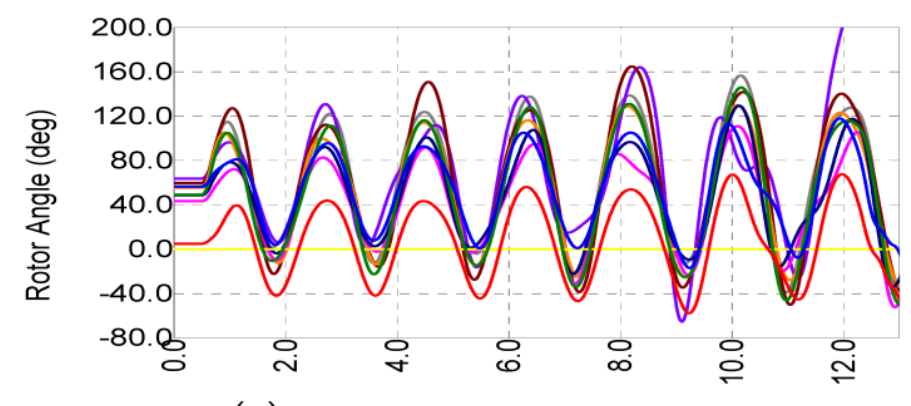

(a)

Time (s)
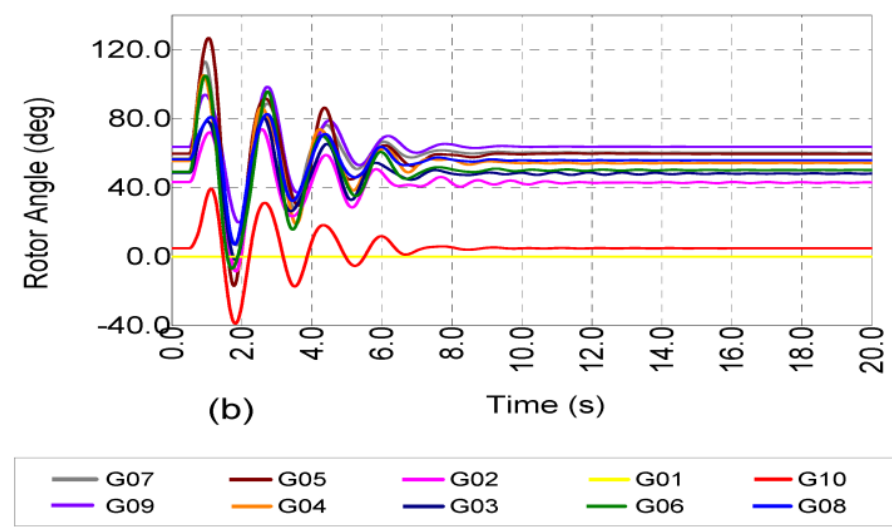

Fig. 6 Rotor angles of SGs for (a) Case 1 (all SGs without PSS) and (b) Case 2 (G5, G7, G9 are equipped with PSS).

The rotor angles of SGs after G7 and G9 are replaced by two equivalent wind farms (case 3) are shown in Fig. 7(a\&b). The test system is affected adversely as a result of replacing SGs equipped with PSSs by an equivalent wind farms. The oscillations in this case last longer than those oscillations in case 2. Moreover, a number of SGs have larger rotor angle magnitude swing than that in the second case. Additionally, Fig. 7 (a\&b) show that representing the wind farm as a single machine has a similar impact on the rotor angle of SGs to representing the wind farm as three machines operating at different modes. These results are similar to those obtained previously in the small signal stability analysis. 

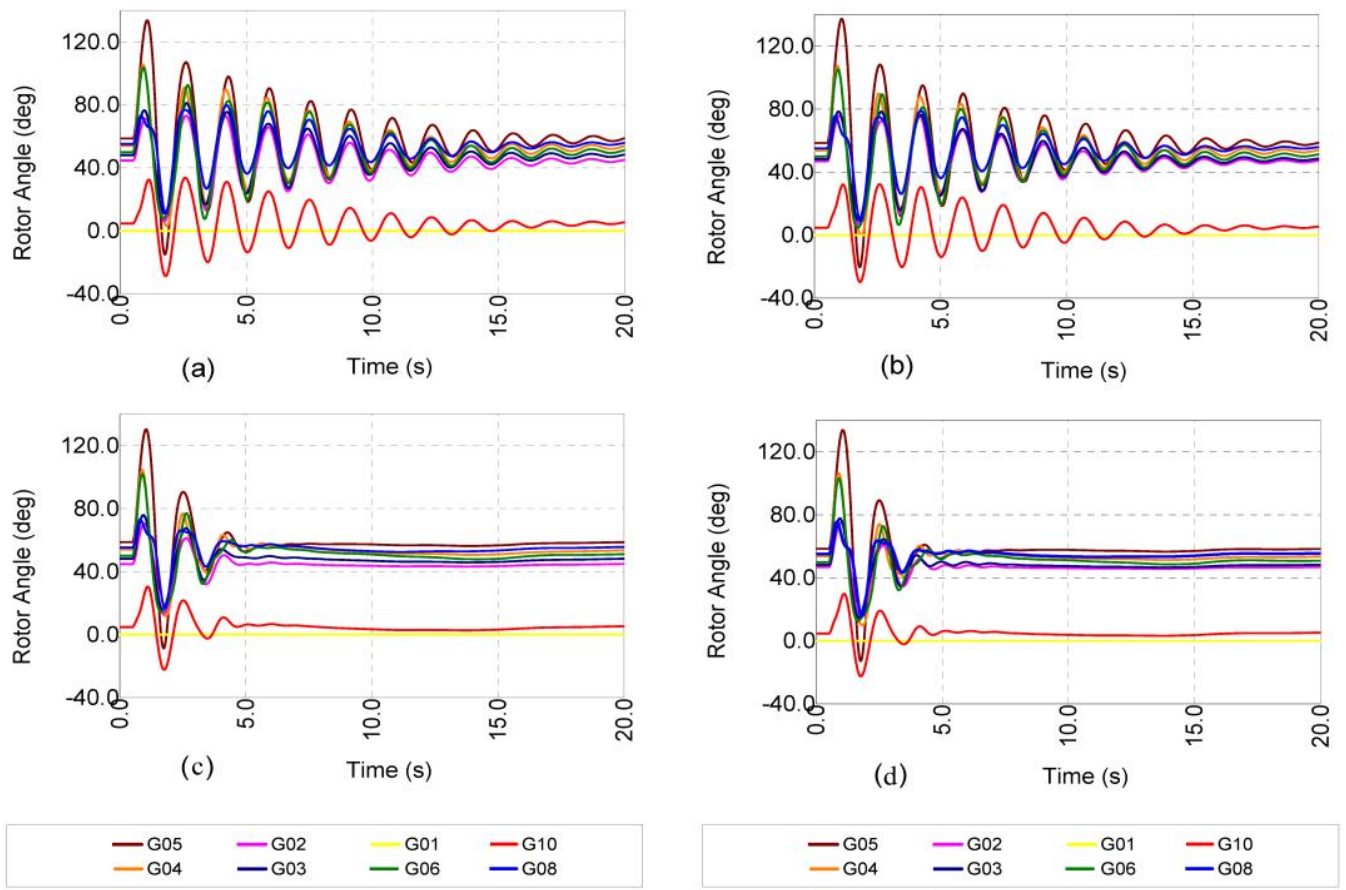

Fig. 7 Rotor angles of SGs for

(a) Case 3 Scenario $A(G 7, G 9$ are each replaced by an equivalent single $D F I G)$

(b) Case 3 Scenario $B(G 7, G 9$ are each replaced by equivalent three $D F I G)$

(c) Case 4 Scenario A (G7, G9 are each replaced by equivalent single DFIG equipped with PSS)

(d) Case 4 Scenario B (G7, G9 are each replaced by equivalent three DFIG equipped with PSS)

It is clear from Fig. 7(c\&d) that the test system can reach steady state in the shortest time by equipping the two wind farms with the proposed PSS. The results of used nonlinear time domain simulation shows that SGs rotor angles oscillations damp quickly and the steady state value of all rotor angles is obtained in less than 5s. Again, the transient stability simulation confirmed that the two scenarios in case 4 are comparable. In both scenarios of this case, the rotor angle oscillations are damped faster than in the case 2 . The results clearly demonstrate that DFIG based wind farms equipped with the proposed PSSs have the ability to damp power system oscillations better than SGs.

Fig. 8 shows the terminal voltages of G7 (bus 36) and G9 (bus 38) for cases 2, 3 and 4 respectively. In case 1 , the terminal voltages of G7 and G9 fall to about $0.6 \mathrm{pu}$ and $0.77 \mathrm{pu}$ respectively for the duration of the fault to improve quickly to their typical values after the disturbance as shown in Fig. 8 (a). On the other hand, in cases 3 and 4, the terminal voltage falls to about $0.2 \mathrm{pu}$ throughout the entire period of the fault followed by improvement to almost 0.6 
pu following the fault clearance and before the disconnecting the crowbar protection system as shown in Fig. 8 (b) and (c) respectively. This is due to the lack of reactive power support from the wind farm throughout the fault and when the protection system retain active. The SGs are producing around 300 MVar over the entire fault period, which in turn enables high voltage levels as can be seen in Fig. 8(a). On the other hand, DFIG based wind farms consume a considerable reactive power amount during the operation of the crowbar time as shown in Fig. 8 (b) and (c) respectively. It is for the reason that DFIGs crowbar is activated following the short circuit and therefore the DFIGs are acting as an induction generator. As soon as the crowbar is switched off, the wind farms reactive power supports their terminal voltages back quickly to their predefined values. However, in case 4, the terminal voltages of the two wind farms vary between 0.9 pu and 1.1 pu for about $4 \mathrm{~s}$ as shown in Fig. 8 (c). This is due to the reactive power variation caused by the attached PSS to the DFIG reactive power controller. As can be seen from cases 3 and case 4 (without and with PSS) results, wind farm reactive power variation is the only difference between the two cases. This difference take place the crowbar deactivated and when the PSSs are started to damp the system oscillations.
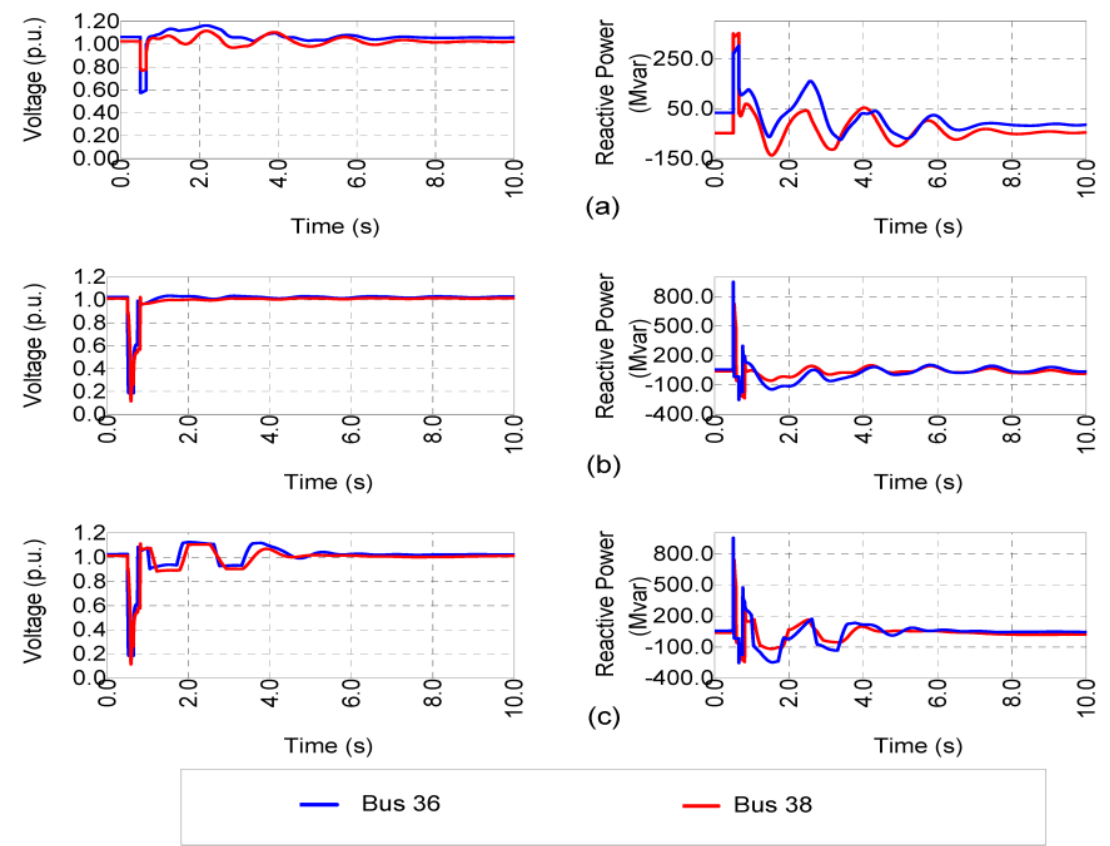

Fig. 8 System transient responses (a) (terminal voltages and reactive power of $G 7$ and $G 9$ in Case 2), (b) (terminal voltages and reactive power of wind farms $1 \& 2$ in Case 3), (C) (terminal voltages and reactive power of wind farms $1 \& 2$ in Case 4) 
Based on the results of small signal and transient stability analysis, damping of power system oscillations is reduced to some extent if a wind farm with DFIG replaced an equivalent conventional SG. However, a satisfactory damping can be achieved by equipping DFIG with the proposed PSS which is connected to the reactive power controller of DFIG-RSC. Simulation results show the effectiveness of the proposed fixed parameters DFIG PSS to damp power system oscillations under a wide range of operating conditions within the wind farm and under various wind speeds. Therefore, a farm level PSS is possible by applying the same PSS signal to the voltage controller of all DFIG wind turbines. Additionally, results from small signal analysis and transient stability analysis demonstrate that the capability of the proposed DFIG PSSs to damp power system oscillations are more superior when compared to those in conventional SGs.

\section{Conclusion}

A comprehensive analysis is conducted in this paper to show the effect of replacing existing synchronous generators equipped with PSSs by equivalent large scale DFIG based wind farms on the damping of power system oscillations in a multi-machine power system. Moreover, a fixed parameters PSS was designed to assess the ability of DFIGs to damp power systems oscillations. Simulation results show that the power oscillation could be affected adversely as a result of replacing SG equipped with PSS by an equivalent wind farm. However, replacing SGs by wind farms fitted with the proposed PSSs can overcome the adverse results. This is illustrated from the simulation results of using the New England 10-machine 39-bus system with two DFIG based wind farms. The results confirm the robustness and stabilizing effect against various operating modes and under various wind speeds. Moreover, the results demonstrate clearly that DFIG equipped with PSS can damp power system oscillations more effectively than SGs PSS. Additionally, based on the obtained results, a farm level PSS is possible by applying the same PSS signal to the voltage controller of all DFIG wind turbines. Such control scheme will be very beneficial as the wind power penetration levels have increased and to allow wind farms with DFIG to take over the responsibility of SGs to damp power system oscillations. 


\section{Appendix}

\section{A. Parameters of PSSs}

Table 3 PSS Parameters used for SGs and DFIGs

\begin{tabular}{|c|c|c|c|c|c|c|c|}
\hline \multicolumn{3}{|c|}{ SGs PSS } & \multicolumn{4}{c|}{ DFIGs PSS } \\
\hline & $K$ & $T_{1}=T_{3}$ & $T_{2}=T_{4}$ & & $K$ & $T 1=T 3$ & $T 2=T 4$ \\
\hline G5 & 18 & 0.4757 & 0.1535 & DFIG1 & 120 & 0.1599 & 0.1325 \\
\hline G7 & 38 & 0.3814 & 0.1851 & DFIG2 & 140 & 0.3179 & 0.2106 \\
\hline G9 & 22 & 0.3533 & 0.0901 & & & & \\
\hline
\end{tabular}

\section{B. DFIG parameters}

Rated power $5 \mathrm{MW}$; rated voltage $3.3 \mathrm{KV}$; rated frequency $50 \mathrm{~Hz}$; number of pole pairs 2; stator resistance $0.00299 \mathrm{pu}$; stator reactance $0.125 \mathrm{pu}$; magnetizing reactance $2.5 \mathrm{pu}$; rotor resistance $0.004 \mathrm{pu}$; rotor reactance $0.05 \mathrm{pu}$; DC-link rated voltage $1200 \mathrm{~V}$; turbine inertia $3.5 \mathrm{~s}$; generator inertia $0.5 \mathrm{~s}$.

\section{References}

[1] G. W. E. Council. Global Wind Energy Outlook (October 2014). Available: http://www.gwec.net/

[2] P. Kundur, Power system stability and control: McGraw-hill New York, 1994.

[3] T. Ackermann, Wind Power in Power Systems: John Wiley \& Sons, 2012.

[4] G. Tsourakis, B. M. Nomikos, and C. D. Vournas, "Contribution of Doubly Fed Wind Generators to Oscillation Damping," Energy Conversion, IEEE Transactions on, vol. 24, pp. 783-791, 2009.

[5] J. L. Domínguez-García, O. Gomis-Bellmunt, F. D. Bianchi, and A. Sumper, "Power oscillation damping supported by wind power: a review," Renewable and Sustainable Energy Reviews, vol. 16, pp. 4994-5006, 2012.

[6] D. Gautam, V. Vittal, R. Ayyanar, and T. Harbour, "Supplementary control for damping power oscillations due to increased penetration of doubly fed induction generators in large power systems," in Power Systems Conference and Exposition (PSCE), 2011 IEEE/PES, 2011, pp. 1-6.

[7] Y. Mishra, S. Mishra, M. Tripathy, N. Senroy, and Z. Y. Dong, "Improving Stability of a DFIG-Based Wind Power System With Tuned Damping Controller," Energy Conversion, IEEE Transactions on, vol. 24, pp. 650660, 2009.

[8] M. Zhixin, F. Lingling, D. Osborn, and S. Yuvarajan, "Control of DFIG-Based Wind Generation to Improve Interarea Oscillation Damping," Energy Conversion, IEEE Transactions on, vol. 24, pp. 415-422, 2009.

[9] F. M. Hughes, O. Anaya-Lara, N. Jenkins, and G. Strbac, "A power system stabilizer for DFIG-based wind generation," Power Systems, IEEE Transactions on, vol. 21, pp. 763-772, 2006. 
[10] M. Edrah, K. L. Lo, A. Elansari, and O. Anaya-Lara, "Power oscillation damping capabilities of doubly fed wind generators," in Power Engineering Conference (UPEC), 2014 49th International Universities, 2014, pp. $1-6$.

[11] S. Muller, M. Deicke, and R. W. De Doncker, "Doubly fed induction generator systems for wind turbines," Industry Applications Magazine, IEEE, vol. 8, pp. 26-33, 2002.

[12] F. Lingling, Y. Haiping, and M. Zhixin, "On Active/Reactive Power Modulation of DFIG-Based Wind Generation for Interarea Oscillation Damping," Energy Conversion, IEEE Transactions on, vol. 26, pp. 513$521,2011$.

[13] F. M. Hughes, O. Anaya-Lara, G. Ramtharan, N. Jenkins, and G. Strbac, "Influence of Tower Shadow and Wind Turbulence on the Performance of Power System Stabilizers for DFIG-Based Wind Farms," Energy Conversion, IEEE Transactions on, vol. 23, pp. 519-528, 2008.

[14] Y. Haiping, F. Lingling, and M. Zhixin, "Reactive power modulation for inter-area oscillation damping of DFIG-based wind generation," in Power and Energy Society General Meeting, 2010 IEEE, 2010, pp. 1-9.

[15] R. D. Fernandez, R. J. Mantz, and P. E. Battaiotto, "Contribution of wind farms to the network stability," in Power Engineering Society General Meeting, 2006. IEEE, 2006, p. 6 pp.

[16] M. Edrah, K. L. Lo, and O. Anaya-Lara, "Impacts of High Penetration of DFIG Wind Turbines on Rotor Angle Stability of Power Systems," Sustainable Energy, IEEE Transactions on, vol. 6, pp. 759-766, 2015.

[17] R. Pena, J. C. Clare, and G. M. Asher, "Doubly fed induction generator using back-to-back PWM converters and its application to variable-speed wind-energy generation," Electric Power Applications, IEE Proceedings , vol. 143, pp. 231-241, 1996.

[18] Q. Wei, G. K. Venayagamoorthy, and R. G. Harley, "Real-Time Implementation of a STATCOM on a Wind Farm Equipped With Doubly Fed Induction Generators," Industry Applications, IEEE Transactions on, vol. 45, pp. 98-107, 2009.

[19] L. Qu and W. Qiao, "Constant power control of DFIG wind turbines with supercapacitor energy storage," Industry Applications, IEEE Transactions on, vol. 47, pp. 359-367, 2011.

[20] M. A. Abido, "A novel approach to conventional power system stabilizer design using tabu search," International Journal of Electrical Power \& Energy Systems, vol. 21, pp. 443-454, 1999.

[21] R. B. Gupta, Hydrogen fuel: production, transport, and storage: CRC Press, 2008.

[22] J. Eichman, K. W. Harrison, and M. Peters, Novel Electrolyzer Applications: Providing More Than Just Hydrogen: National Renewable Energy Laboratory, 2014.

[23] N. Yang, Q. Liu, and J. D. McCalley, "TCSC controller design for damping interarea oscillations," Power Systems, IEEE Transactions on, vol. 13, pp. 1304-1310, 1998.

[24] N. Mendis, K. M. Muttaqi, S. Perera, and S. Kamalasadan, "An Effective Power Management Strategy for a Wind-Diesel-Hydrogen-Based Remote Area Power Supply System to Meet Fluctuating Demands Under Generation Uncertainty," Industry Applications, IEEE Transactions on, vol. 51, pp. 1228-1238, 2015. 
[25] M. Kiaee, A. Cruden, D. Infield, and P. Chladek, "Utilisation of alkaline electrolysers to improve power system frequency stability with a high penetration of wind power," IET Renewable Power Generation, vol. 8, pp. 529-536, 2013.

[26] M. PY̌ller and S. Achilles, "Aggregated wind park models for analyzing power system dynamics," 2003.

[27] V. Akhmatov and H. Knudsen, "An aggregate model of a grid-connected, large-scale, offshore wind farm for power stability investigations-importance of windmill mechanical system," International Journal of Electrical Power \& Energy Systems, vol. 24, pp. 709-717, 2002.

[28] B. Busarello, NEPLAN, power system analysis, Cott+ Partner AG, 2013[Online]. Available: www. neplan. ch 